DE GRUYTER
OPEN

DOI: $10.1515 /$ plass-2017-0017

Jarosław Plich*, Beata Tatarowska

Plant Breeding and Acclimatization Institute - National Research Institute, Młochów

Research Center, Platanowa Str. 19, 05-831 Młochów, Poland;

*Corresponding author: j.plich@ihar.edu.pl

FIELD EVALUATION OF POTATO RESISTANCE AGAINST PHYTOPHTHORA INFESTANS UNDER NATURAL INFECTION PRESSURE

\begin{abstract}
Although development of potato cultivars resistant to late blight has long been one of the primary goals of potato breeding programs, several different methods of field resistance evaluation have been used by potato breeders. Recently, within the EucaBlight network (www.euroblight.net), common methods of late blight evaluation have been agreed on, and these methods are currently highly recommended for use by all those interested in evaluating the resistance of the potato to late blight. Here, we describe a method of evaluating potato resistance in field conditions routinely used at Młochów Research Center, which is compliant with recommendations of the EucaBlight protocol.
\end{abstract}

Keywords: field trials, late blight resistance, rAUDPC, method

\title{
INTRODUCTION
}

Testing the resistance to Phytophthora infestans in field conditions is a very important element of selecting resistant breeding lines and evaluating new potato cultivars. Although resistance tests performed in laboratory conditions (such as the detached leaflet tests) are less laborious and time-consuming, the laboratory tests are only a rough estimation of the field resistance, and it is performance of plants in the field that interests potato breeders and growers. In many cases, potato clones/cultivars with high a level of race-non-specific (horizontal) resistance present the full scope of their resistance only in field experiments, while in laboratory tests they are susceptible (Plich et al., 2015). Also, in case of some $R$-genes the resistance to late blight can be observed in field experiments, but not in laboratory conditions (Jo et al., 2011).

Communicated by Ewa Zimnoch-Guzowska 
The results of the field experiments are greatly influenced by environmental conditions (the weather and the population composition of $P$. infestans) and the type of examined material (the type of resistance, maturity). Therefore, comparison across experiments and years can only be made when a set of standard cultivars with a known resistance level is employed (Sieczka, 2001). Field resistance tests can be performed under natural infection pressure, or using artificial inoculation with a specific $P$. infestans isolate, or a combination of isolates can be applied (www.euroblight.net). An experiment under natural infection should be performed in a location where the weather conditions are favorable to late blight infection, and in which complex races of $P$. infestans are present.

At Młochów Research Center, field resistance tests are routinely performed to evaluate advanced breeding lines, new cultivars, as well as the unselected progeny of the potato according to Sieczka (2001). The experimental fields are located in the Advisory Center for Agriculture in Boguchwała (Southeast Poland), where relatively constant high infection pressure by complex races of $P$. infestans has been observed over several vegetation seasons.

\section{PLANTING OF THE MATERIAL}

Potato clones/cultivars are usually planted in the last week of April on 6 hill plots according to the RCB (Randomized Complete Block) design with 2 or 3 blocks (replications). Along with the examined materials, a set of standard cultivars as well as a set of Black's differentials are also planted. The standard cultivars with a known level of resistance (susceptible: Alpha, Bintje, Eersteling; moderately susceptible: Gloria; moderately resistant: Robijn, Escort; and highly resistant: Sárpo Mira) were chosen according to the EucaBlight protocol recommendation (www.euroblight.net). The set of Black's differentials is always included in the experiment to assess the virulence profiles of local populations of $P$. infestans. Every two rows of the experimental plots are interspersed with a single row of a moderately susceptible cultivar to separate the plots and to ensure a reliable source of inoculum during the epidemic period.

\section{SCORING}

Starting from the second half of June, plants in the experimental field are examined for the first symptoms of $P$. infestans infection on the more susceptible clones/cultivars. The first late blight symptoms appear on the lowest leaves of the canopy (or sometimes on the stems) of susceptible cultivars at the beginning of July or even at the end of June. The typical late blight symptoms are brownish or blackish water-soaked lesions on the leaves or stems. Down-side of the leaves manifest the necrosis, and the whitish sporulation (mycelium) is usually observed. The sporulation can also be observed on the upper side of the leaf on the margin of the lesion. Once late blight appears in the experimental field, all the examined clones/cultivars are assessed once a week. The degree of infection of each plot is expressed as percentage of late blight-symptomatic canopy, or alternatively scores as per the 1-9 scale (Table 1 ). 
Assessment of field resistance of the potato to $P$. infestans according to 9-degree scale (Sieczka, 2001)

\begin{tabular}{clcc}
\hline \multirow{2}{*}{ Score } & \multicolumn{1}{c}{ Observed symptoms of infection } & \multicolumn{2}{c}{ Percent of infection } \\
\cline { 3 - 4 } & & Range & Mean \\
\hline 9 & No symptoms, occasional necrotic spots & $1.0-0.5$ & 0.2 \\
8 & Occasional spots on individual plants, 2 leaves per plant infected & $0.6-2.3$ & 1.1 \\
7 & Slight infection on 9 leaves & $2.4-9.5$ & 4.7 \\
6 & All plants infected, about 20\% leaves infected & $9.6-32.0$ & 18.3 \\
5 & $50 \%$ of leaves blighted, petioles infected & $32.1-67.9$ & 50.0 \\
4 & $80 \%$ of leaves blighted, petioles and steams infected & $68.0-90.4$ & 81.7 \\
3 & Heavy infection, about 9 leaves healthy & $90.5-97.7$ & 95.3 \\
2 & Very heavy infection, individual leaves still green & $97.8-99.5$ & 98.9 \\
1 & Plants completely blighted, occasionally parts of stems not infected & $99.6-100$ & 99.8 \\
\hline
\end{tabular}

\section{DATA ANALYSIS AND INTERPRETATION}

Based on at least 5 (usually 6-8) informative readings the Area Under Disease Progress Curve (AUDPC) is calculated, according to Fry's (1978) formula:

$$
A U D P C=\sum_{i=1}^{n}\left[\frac{\left(x_{i+1}+x_{i}\right)}{2}\right] \times\left[t_{i=1}-t_{i}\right]
$$

where:

$x_{i}$ - the percentage of foliage destruction in $i$-th observation

$t_{i}-$ days at the $i$-th observation

$n$ - the total number of observations.

The AUDPC value is generally not comparable across experiments and to standardize it, the relative AUDPC (rAUDPC) is calculated. The rAUDPC is calculated by dividing the AUDPC value by the total area of maximum potential AUDPC (the total number of days between the first and the last observation multiplied by $100 \%$ ). The range of rAUDPC values ranges from 0.0 to 1.0 , with low values corresponding to high resistance. To ensure reliable assessments and confirm effectiveness of resistance in various weather conditions and against various populations of $P$. infestans, resistance assessment should be repeated during at least three vegetative periods and, if it is possible performed in multiple locations.

\section{ACKNOWLEDGMENTS}

This work was carried out as a part of the statutory project No 1-3-00-3-01 of the Plant Breeding and Acclimatization Institute - National Research Institute. 


\section{REFERENCES}

Fry W. E. 1978. Quantification of general resistance of potato cultivars and fungicide effects for integrated control of potato late blight. Phytopathology 68: 1650-1655.

Jo K. R., Arens M., Kim T. Y., Jongsma M. A., Visser R. G. F., Jacobsen E., Vossen J. H. 2011. Mapping of the $S$. demissum late blight resistance gene $R 8$ to a new locus on chromosome IX. Theor. Appl. Gen. 123: $1331-1340$.

Plich J., Tatarowska B., Lebecka R., Śliwka J., Zimnoch-Guzowska E., Flis B. 2015. R2-like gene contributes to resistance to Phytophthora infestans in Polish potato cultivar Bzura. Am. J. Potato Res. 92(3): 350 358 .

Sieczka M. 2001. Evaluation of resistance to Phytophthora infestans under natural infection pressure. In: The methods of evaluation and selection applied in potato research and breeding. Ed. H.J. Czembor. Monografie i Rozprawy Naukowe IHAR Radzików, 10a/2001: 72-74.

www.euroblight.net/protocols 